\title{
Importancia de los coliformes fecales como indicadores de contaminación en la Franja Litoral de Bahía de Banderas, Jalisco-Nayarit.
}

\section{Carta al Editor}

María del C. Cortés-Lara.

Centro Universitario de la Costa, Campus Puerto Vallarta, Universidad de Guadalajara, Jalisco, México.

Hoy en día, la contaminanción de nuestro entorno está considerada como un serio problema que incluye varios aspectos como la salud pública. Particularmente, las descargas de aguas negras son una fuente importante de contaminación de las zonas costeras. En éstas, un gran número de bacterias patógenas y virus, como estreptococos, estafilococos, Salmonella, Shigella, Vibrio, virus de la hepatitis y la poliomielitis son descargados en el océano representando un riesgo para la salud por la propagación de enfermedades infecciosas. De igual forma, representan un riesgo para la salud en las personas consumidoras de moluscos bivalvos y para los bañistas en playas contaminadas. Algunos microorganismos logran sobrevivir en concentraciones suficientes ocasionando enfermedades, principalmente a bañistas, como tifoidea, paratifoidea, gastroenteritis, hepatitis y poliomielitis (1). Tomando en cuenta lo anterior, en esta nota se presentan algunos resultados preliminares de la calidad bacteriológica del agua de mar en la franja litoral de Bahía de Banderas, los cuales serán de utilidad en futuros estudios ambientales. Los organismos utilizados como indicadores biológicos de contaminación fueron las bacterias coliformes fecales por las ventajas que representan, entre ellas se pueden mencionar las siguientes:

Se considera que niveles bajos de coliformes fecales son buenos indicadores de ausencia de organismos patógenos.

Su evaluación es realtivamente simple y directa.

Su concentración en aguas residuales (unos 100 millones/100 mililitros) es más alta que la de patógenos fecales.

No se multiplican fuera del tracto intestinal de animales de sangre caliente

Su presencia en sistemas acuáticos es evidencia de contaminación de origen fecal (2).

En Bahía de Banderas se realizaron una serie

Solicitud de sobretiros: M.C. María del C. Cortés-Lara, Departamento de Ciencias, Centro Universitario de la Costa, campus Puerto Vallarta. Universidad de Guadalajara, Ave. Universidad \# 203, Deleg. Ixtapa, C.P. 48280, Puerto Vallarta, Jalisco, México.

Fax:01-322-1-05-20 y 21. Correo electrónico: carmenc@pv1.udg.mx y alevi@pv.udg.mx

Recibido el 11/Febrero/2003. Aceptado para publicación el 7/Abril/2003. 
M del C Cortés Lara.

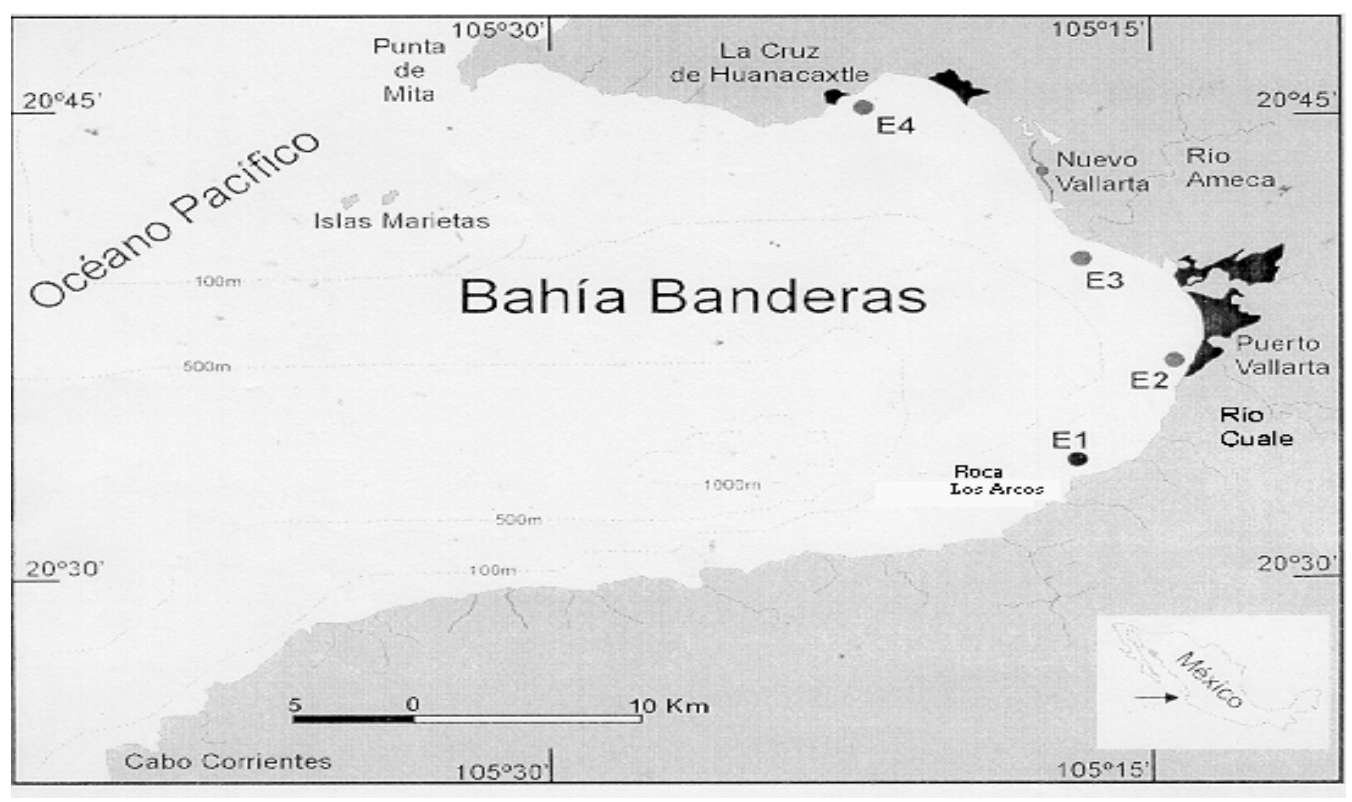

Figura 1.- Ubicación del área de estudio y localización de los sitios de muestreo.

de monitoreos bimensuales desde el 2000 al 2002 en cuatro estaciones de muestreo, debido a que sus costas reciben significativas descargas de aguas negras de la ciudad de Puerto Vallarta y comunidades aledañas como Nuevo Vallarta, Bucerías, La Cruz de Huanacaxtle y Punta de Mita entre otras. Aunado a lo anterior, sus playas son utilizadas por el turismo y la población residente pudiendo constituir un problema de higiene y de salud públca.

COLIFORMES FECALES

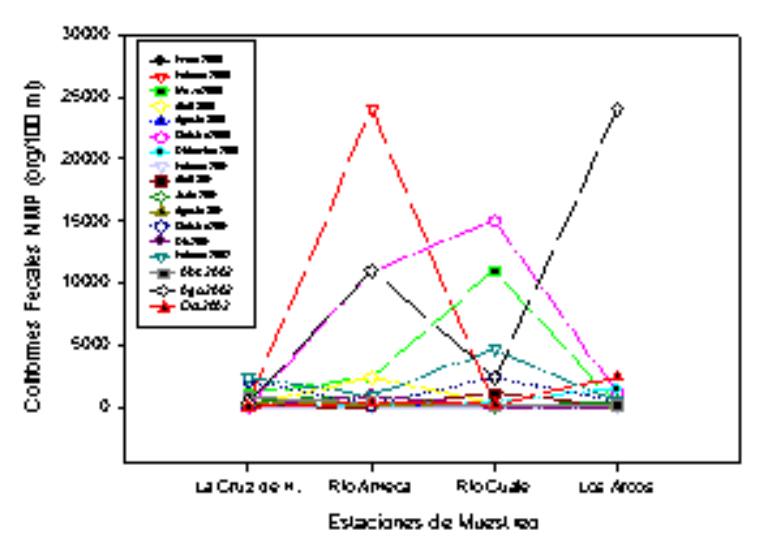

Figura 2.- Distribución y abundancia de las bacterias coliformes fecales en muestras superficiales de la Bahía de Banderas Jalisco-Nayarit. Datos comparativos del 2000 al 2002.
Los resultados de la distribución espaciotemporal de las bacterias coliformes fecales en el agua de mar se reportan en la figura 2 en donde se puede apreciar que las estaciones del Río Ameca (E-3) y el Río Cuale (E-2) presentan una mayor concentración rebasando en algunos casos, los límites permisibles de acuerdo a la Norma Oficial Mexicana de >200 $\mathrm{NMP} / 100 \mathrm{ml}$ (3). En general, se notó una considerable variación de las bacterias indicadoras desde 3 hasta $24,000 \mathrm{org} / 100 \mathrm{~mL}$. Esto tiene gran importancia para la determinación de la calidad sanitaria del agua costera de Bahía de Banderas, ya que los valores reportados son evidencia de contaminación de origen fecal en el sistema.

La fluctuación de estos valores se puede atribuir a las aguas de desecho doméstico que descargan sus heces al medio marino, a granjas, chiqueros y restaurantes que no cuentan con medios de sanidad. Por otro lado, los valores indicativos de bacterias coliformes muestran que el sistema de tratamiento de aguas negras necesita ser mejorado y ampliado en cuanto a su capacidad se refiere. Es muy importante considerar estos valores ya que autores como Grunnet (4) señalan que en concentraciones mayores de 1,000 coliformes fecales/ml hay un $50 \%$ de probabilidad de encontrar Salmonella sp.

\section{Revista Biomédica}


Finalmente, es importante señalar que la detección de bacterias coliformes, incluso en áreas de uso recreativo, refleja que la contaminación microbiana en la Bahía de Banderas es significativa. (Rev Biomed 2003; 14:121-123)

Palabras clave: Coliformes fecales, indicadores de contaminación, Bahía de Banderas, Jalisco.

\section{REFERENCIAS.}

1.- Delgadillo-Hinojosa F, Orozco-Borbón MV. Bacterias Patógenas en sedimeinto de la Bahía de Todos Santos, Baja California. Ciencias Marinas 1987; 13: 31-38.

2.- Wong Chang I, Barrera-Escorcia G. Implicaciones ecológicas de la contaminación microbiológica en la zona costero-marina. En: Botello AV, Rojas-Galaviz JL, Benítez JA, Zárate-Lomelí D, editores. Golfo de México, Contaminación e Impacto Ambiental: Diagnóstico y Tendencias. Universidad Autónoma de Campeche. EPOMEX Serie Científica; 1996. 369-376.

3.- Norma Oficial Mexicana: NOM-003-ECOL-1997. Disponible en: URL: http://www.ecologia.campeche.gob.mx/consultas/ normas/oficial/ine_003.htm.

4.- Grunnet, K. Selected Microorganisms for Coastal Pollution. Studies and Coastal Pollution Control. 1978; 3: 759-

75. 